\title{
Structural and functional results of indirect diode laser treatment for retinopathy of prematurity from 1999 to 2003 in Kuwait
}

This article was published in the following Dove Press journal:

Clinical Ophthalmology

I February 2013

Number of times this article has been viewed

\author{
Vivek B Wani ${ }^{1,2}$ \\ Khalid Al Sabti ${ }^{1,3}$ \\ Niranjan Kumar' \\ Seemant Raizada' \\ Jamal Al Kandari' \\ Mohammad Al Harbi ${ }^{4}$ \\ Rima Sawaan ${ }^{5}$ \\ Usha Rajaram ${ }^{6}$ \\ Niran Al-Naqeeb ${ }^{7}$ \\ Mumtaz Shukkur ${ }^{8}$ \\ 'Department of Ophthalmology, \\ Al Bahar Ophthalmology Center, \\ Kuwait city, Kuwait; ${ }^{2}$ Department \\ of Ophthalmology, Al Adan Hospital, \\ Al Adan, Kuwait; ${ }^{3}$ Department of \\ Surgery, Faculty of Medicine, Jabriya, \\ Kuwait; ${ }^{4}$ Department of Neonatology, \\ Al Sabah Maternity Hospital, Kuwait \\ City, Kuwait; ${ }^{5}$ Department \\ of Neonatology, Al Farwaniya Hospital, \\ Al Farwaniya, Kuwait; ${ }^{6}$ Department of \\ Neonatology, Al Jahra Hospital, \\ Al Jahra, Kuwait; ${ }^{7}$ Department \\ of Neonatology, Al Adan Hospital, \\ Al Adan, Kuwait; ${ }^{8}$ Department \\ of Community Medicine, Faculty \\ of Medicine, Jabriya, Kuwait
}

Purpose: The purpose was to report the structural, visual, and refractive outcomes of infants treated for retinopathy of prematurity (ROP) with laser and to identify the risk factors for unfavorable outcomes.

Materials and methods: The charts of infants with severe ROP treated by diode laser in a tertiary center during the period April 1999 to November 2003 were reviewed. Treated infants were followed up for fundus examination, visual acuity assessment, and cycloplegic refraction. Data regarding ocular risk factors, like zones of ROP and the extent of extraretinal proliferations, and data regarding various systemic risk factors were collected. A minimum follow up of 6 months was needed for inclusion in the study of structural outcome. A minimum follow up of 24 months was needed for the study of visual and refractive outcomes. The outcomes measured were: rate of unfavorable structural outcome, unfavorable visual outcome (visual acuity $<20 / 40$ ), and high myopia (myopia $\geq 5$ diopters). The ocular and systemic risk factors were studied for their significance in the development of unfavorable outcomes.

Results: Two hundred seventy eyes of 148 infants were treated for severe ROP, out of which 20 eyes $(7.4 \%)$ had unfavorable structural outcome. Visual data were available for 149 eyes of 81 infants, of which 70 eyes (47\%) had unfavorable visual outcome. Refractive data were available for 131 eyes of 72 infants, and high myopia was present in $23(17.6 \%)$ eyes. Zone I disease was the significant risk factor for unfavorable structural $(P<0.0001)$, unfavorable visual outcome $(P=0.03)$, and for high myopia $(P<0.0001)$. Lower postconceptional age at treatment was significant for unfavorable structural outcome $(P=0.03)$ and high myopia $(P<0.0001)$. Presence of sepsis $(P=0.029)$ and extraretinal proliferation $\geq 6$ hours were significant for unfavorable structural outcome $(P=0.002)$.

Conclusion: ROP in zone I was the most significant risk factor for all the unfavorable outcomes. Laser-treated ROP infants need long term follow up.

Keywords: structural outcome, refractive outcome, visual outcome, unfavorable outcome, risk factors for unfavorable outcomes

\section{Introduction}

Retinopathy of prematurity (ROP) is an important preventable cause of childhood blindness. ${ }^{1}$ The cryotherapy for retinopathy of prematurity study (CRYO-ROP) ${ }^{2}$ established the benefit of treatment for threshold ROP, in reducing the risk of blindness. Transpupillary diode laser photocoagulation (TDLP) for threshold ROP, through indirect ophthalmoscope delivery, has become an effective alternative to cryotherapy because of lesser morbidity, easier accessibility to the posterior retina without the need to open the conjunctiva, and better structural and functional outcomes. ${ }^{3-7}$ Structural and functional results for threshold ROP after TDLP have been published, with
Correspondence: Vivek B Wani

PO Box 17672, Khaldiya,

PC code 72457, Kuwait

Tel +965 24880924

Fax +965248I 1314

Emailvbwani@yahoo.com 
varying periods of follow up. ${ }^{3-4,8-15}$ The incidence of ROP and of threshold disease have both been reported from the Middle East, ${ }^{16,17}$ but to the best of our knowledge, there are no studies from the region regarding structural, refractive, and functional results of TDLP for threshold ROP.

In this study, we aim to study the structural and functional outcomes of infants who underwent TDLP in our center from August 1999 to November 2003 and to identify the risk factors for unfavorable outcomes. This study was conducted before the introduction of the Early Treatment of Retinopathy of Prematurity (ETROP) study ${ }^{18}$ guidelines in our center.

\section{Materials and methods}

The study was approved by the Institutional Ethics Committee of Al-Bahar Ophthalmology Centre, Kuwait. We identified the infants treated for ROP by TDLP from the operation theater register of the hospital, as this procedure was conducted in the operation theater during the study period. Screening of the babies was done at the neonatal intensive care units of four hospitals of the Ministry of Health of Kuwait, namely, Al Sabah Maternity Hospital, Al Farwaniya Hospital, Al Jahra Hospital, and Al Adan Hospital. However, the laser treatment was carried out at the Al-Bahar Ophthalmology Centre, Kuwait. The procedures for screening and treatment for ROP followed in this study are similar to those described elsewhere. ${ }^{17}$ Based on the observations that lesser circumferential involvement at the time of treatment leads to better structural outcomes, ${ }^{19,20}$ our criteria for treatment of ROP were stage $3+$ in zone I or II, with extraretinal proliferations (ERP) of at least 3 clock hours (h) contiguously or 5 clock h cumulatively. We called this "modified threshold disease."17 Zone I was the circular area of retina the radius of which extends from the center of the disc to twice the distance from the center of the disc to the center of the macula, and zone II was the retinal area extending centrifugally from the edge of the zone I to the nasal ora serrata.

The screening guidelines of the Ministry of Health hospitals of Kuwait included all infants born with birth weight (BW) of $1500 \mathrm{~g}$ or less and/or at gestational age (GA) of 34 weeks or less. The laser procedure was carried out in the operation theatre, in the presence of the neonatologist. The entire avascular retina, from the ridge to the ora serrata, was treated in a near confluent manner using a Diode Laser Indirect Ophthalmoscope (Oculight ${ }^{\circledR} \mathrm{SL}$, Iridex Corp, Mountain View, CA, USA). The laser treatment was done by VBW, NK, or SR, who are trained vitreoretinal specialists, with experience in the use of the indirect diode laser; if follow-up examinations showed persistent plus disease with the presence of active ERP, then such eyes were retreated to cover the skipped areas. Once the ROP showed regression, the infants were followed up every 6 months to 1 year. During each visit, the infants were examined for the pattern of fixation, presence of strabismus, and cycloplegic refraction, with Cyclopentolate 1\% eye drops. Fundus examination was done by indirect ophthalmoscopy. The best corrected visual acuity in each eye was checked with Cardiff cards at a $50 \mathrm{~cm}$ distance in the preverbal age group, and the Snellen equivalent was noted. In those children who were able to communicate, visual acuity was measured with the Snellen visual acuity chart.

The case charts were reviewed to collect the data regarding sex, GA at birth, BW, whether product of single or multiple pregnancy, number of ventilated days, presence of intraventricular hemorrhage (IVH), and sepsis. The eye, zone of ROP, the circumferential extent of ERP, postconceptional age (PCA) at treatment and need for retreatment were noted. Details of further vitreoretinal surgeries, if any, and their results were noted. The anatomical status of the retina, best corrected visual acuity, spherical equivalent (SE) refraction (spherical value plus half the cylinder value) in each eye, presence of strabismus, and duration of follow up in months were recorded.

The outcomes studied were: (a) unfavorable structural outcome, defined as per the CRYO-ROP study; ${ }^{2}$ (b) unfavorable visual outcome, defined as visual acuity of less than 20/40; and (c) unfavorable refractive outcome - high myopia, defined as myopia $\geq 5$ diopters (D). ${ }^{14}$

For subjects to be included in the study of unfavorable structural outcome, a minimum follow up of 6 months was needed. For visual and refractive outcomes, subjects with a minimum follow up of 24 months were included. Those who did not meet these criteria were excluded from the study.

\section{Statistical analysis}

All data were entered into a spreadsheet and analyzed using PASW for Windows statistical software Version 18.0 (IBM, Armonk, NY, USA). Chi square test was used for categorical variables and Student $t$-test was used for linear independent variables.

A $P$-value of 0.05 or less was considered statistically significant. To study the significance of systemic factors for unfavorable structural outcome, infants with unfavorable structural outcome in at least one eye were compared with those who had favorable outcome in both eyes. To study the significance of ocular risk factors, like ERP and zone of 
the ROP, for unfavorable structural outcome, all the studied eyes with unfavorable outcome were grouped together and compared with eyes with favorable outcome. The same principles were applied for the study of unfavorable visual and refractive outcomes.

\section{Results}

One hundred forty-eight infants had a minimum follow up of 6 months and were eligible to be included in the study. We excluded seven infants who had died within 3 months of treatment and four who were lost to follow up. Out of the remaining 148 infants, 81 infants had follow up of at least 24 months and visual data were available for them. Out of these 81 infants, refractive data were available for only 72 infants, and these 72 infants were included in the study of refractive outcome. The demographic features of these 148, 81, and 72 infants are given in Table 1. The prevalence of systemic and ocular risk factors among these infants is shown in Table 2.

\section{Structural outcomes}

Two hundred seventy eyes of 148 infants were treated by laser for severe ROP during the study period. The mean follow up of the 148 infants was 23 months \pm 17.0 months (range; 6-96 months). One hundred twenty-two infants $(82.4 \%)$ were treated bilaterally and $26(17.6 \%)$ unilaterally. Regression of the disease was seen with first treatment in all except 47 eyes $(17.2 \%)$ that needed retreatment of skipped areas. Twenty eyes of 13 infants (seven infants, bilaterally; and six, unilaterally) showed progression of ROP and the rest regressed; out of these 20 eyes, eleven eyes developed stage 5 (total retinal detachment), eight developed stage 4B (partial retinal detachment involving the fovea), and one developed stage 4A (extrafoveal partial retinal detachment).

Eight eyes underwent pars plicata vitrectomy and the one eye with stage $4 \mathrm{~A}$ underwent scleral buckling, and the remaining eleven eyes were not operated upon. Out of the eight eyes operated, two eyes had a reattached posterior pole. The one case of stage 4A eye, which underwent scleral buckling, had an attached retina with severe dragging of the macula and disc. In summary, $20(7.4 \%)$ eyes of $13(8.8 \%)$ infants had an unfavorable structural outcome irrespective of the outcome of further surgeries. Among those with favorable structural outcome, seven eyes $(2.8 \%)$ had disc dragging, with macular heterotopia.

There were 50 (18.5\%) eyes with ROP in zone I and 220 $(81.5 \%)$ eyes with ROP in zone II. The mean ERP in the 270 eyes was $4.5 \mathrm{~h} \pm 2.2 \mathrm{~h}$ (range $2-12 \mathrm{~h}$ ). There were seven eyes in which the treatment was carried out even when the ERP was only $2 \mathrm{~h}$ because of the severe nature of the plus disease.

Two hundred eyes were treated according to our aimed guidelines of the extent of stage $3+$, and 70 eyes were treated after they had exceeded our criteria.

For unfavorable structural outcome, the presence of sepsis $(P=0.026$, Chi square), lower PCA at treatment $(P=0.03$, $t$-test), zone I disease $(P<0.0001$, Chi square $)$, and treatment of the eyes with ERP $\geq 6 \mathrm{~h}(P=0.002$, Chi square test) were significant (Table 3 ). Males were more likely to have unfavorable outcome than females, although the $P$-value did not meet statistical significance $(P=0.054)$.

However, BW, GA, single or multiple births, presence of IVH, and number of ventilated days were not found to be significant risk factors for unfavorable structural outcome.

Table I Demographic characteristics of infants

\begin{tabular}{|c|c|c|c|}
\hline Characteristics & Structural outcome & Visual outcome & Refractive outcome \\
\hline \multicolumn{4}{|l|}{ Number of infants } \\
\hline Number (\%) & $148(100)$ & $81(100)$ & $72(100)$ \\
\hline \multicolumn{4}{|l|}{ Number of eyes studied } \\
\hline Number (\%) & $270(100)$ & $149(100)$ & $|3|(100)$ \\
\hline \multicolumn{4}{|l|}{ BW (g) } \\
\hline Mean & 910.8 & 903.5 & 900 \\
\hline Range; \pm SD & $490-1650 ; 203.2$ & 490-I473; 199.5 & $490-1473 ; 203.4$ \\
\hline \multicolumn{4}{|l|}{ GA (weeks) } \\
\hline Mean & 27.4 & 27.4 & 27.4 \\
\hline Range; \pm SD & $24-34 ; 1.9$ & $24-34 ; 2.1$ & $24-34 ; 2.1$ \\
\hline \multicolumn{4}{|l|}{ Sex } \\
\hline Female, number (\%) & $66(45)$ & $35(43.2)$ & $33(45.8)$ \\
\hline Male, number (\%) & $82(55)$ & $46(56.8)$ & $39(54.2)$ \\
\hline \multicolumn{4}{|l|}{ Follow up (months) } \\
\hline Mean & 23.0 & 35 & 36 \\
\hline Range; \pm SD & $6-96 ; \pm 17.0$ & $24-96 ; \pm 14$ & $24-96 ; \pm 14.2$ \\
\hline
\end{tabular}

Abbreviations: BW, birth weight; GA, gestational age at birth; SD, standard deviation. 
Table 2 Prevalence of systemic and ocular risk factors among infants studied for structural, visual, and refractive outcomes

\begin{tabular}{|c|c|c|c|}
\hline Characteristics & $\begin{array}{l}\text { Structural } \\
\text { outcome }\end{array}$ & $\begin{array}{l}\text { Visual } \\
\text { outcome }\end{array}$ & $\begin{array}{l}\text { Refractive } \\
\text { outcome }\end{array}$ \\
\hline \multicolumn{4}{|l|}{ Pregnancy } \\
\hline Single, n (\%) & 102 (68.9) & $53(65.4)$ & $44(61.1)$ \\
\hline Multiple, n (\%) & $46(31.1)$ & $28(34.6)$ & $28(38.9)$ \\
\hline \multicolumn{4}{|l|}{ IVH } \\
\hline Present, n (\%) & $67(45.3)$ & $39(48.1)$ & $33(45.8)$ \\
\hline Absent, n (\%) & $81(54.7)$ & $42(51.9)$ & $39(54.2)$ \\
\hline \multicolumn{4}{|l|}{ Sepsis } \\
\hline Present, n (\%) & $76(51.4)$ & $50(61.7)$ & $42(58.3)$ \\
\hline Absent, n (\%) & $72(48.6)$ & 31 (38.3) & $30(41.7)$ \\
\hline \multicolumn{4}{|l|}{ Ventilated days } \\
\hline Mean \pm SD & $24.0 \pm 20.3$ & $25.8 \pm 20.7$ & $26.6 \pm 20.8$ \\
\hline Range & 0-98 & $0-98$ & $0-98$ \\
\hline \multicolumn{4}{|l|}{ Eye zone } \\
\hline Zone I n (\%) & $50(18.5)$ & $38(25.5)$ & $25(19.1)$ \\
\hline Zone II n (\%) & $220(8 I .5)$ & III (74.6) & $106(80.9)$ \\
\hline \multicolumn{4}{|l|}{ PCA (weeks) } \\
\hline Mean \pm SD & $37.4 \pm 2.2$ & $37.2 \pm 2.0$ & $37.3 \pm 1.9$ \\
\hline Range & $32-47$ & $32-43$ & $4-43$ \\
\hline \multicolumn{4}{|l|}{ ERP } \\
\hline Mean \pm SD & $4.5 \pm 1.8$ & $4.5 \pm 1.8$ & $4.4 \pm 1.6$ \\
\hline Range & $2-12$ & $2-10$ & $2-10$ \\
\hline
\end{tabular}

Abbreviations: IVH, intraventricular hemorrhage; SD, standard deviation; PCA, postconceptional age (at treatment); ERP, extraretinal proliferation.

\section{Visual outcomes}

Visual data were available for 149 eyes (75 right and 74 left eyes) of 81 infants who had completed a minimum follow up of 24 months. Sixty-eight subjects had laser treatment of both eyes and 13 had laser treatment in only one eye. Table 4 shows the distribution of visual acuity in the right and left eyes. Seventy-nine eyes (53\%) achieved visual acuity of $20 / 40$ or better. Unfavorable structural outcome was present among seven infants bilaterally and three infants unilaterally, in this group of 81 subjects. Four eyes had dragged disc and macular heterotopias. One child had bilateral optic atrophy due to hydrocephalus, and another child had cerebral palsy. Twenty-one (25.9\%) infants had strabismus, in this group of 81 infants. Zone I disease was present in 38 eyes (25.5\%), and the mean ERP in the 149 eyes was $4.5 \mathrm{~h} \pm$ standard deviation (SD) $1.8 \mathrm{~h}$ (range $2-10 \mathrm{~h}$ ).

The significant risk factor for unfavorable visual outcome (vision $<20 / 40)$ was zone I disease $(P=0.002$, Chi square test). Other systemic or ocular risk factors were not found to be significant for unfavorable visual outcome.

\section{Refractive outcomes}

Refractive data were available for 131 (66 right and 65 left) eyes of 72 infants. Table 5 shows the distribution of refractive errors in right and left eyes.
Table 3 Risk factors found significant for unfavorable outcomes

\begin{tabular}{|c|c|c|c|}
\hline Risk factor & Favorable & Unfavorable & $P$-value \\
\hline \multicolumn{4}{|c|}{ Significant risk factors for unfavorable structural outcome } \\
\hline \multicolumn{4}{|l|}{ Sepsis } \\
\hline Present & 65 & II & $0.026(t$-test $)$ \\
\hline Absent & 70 & 2 & \\
\hline \multicolumn{4}{|l|}{ ERP criteria } \\
\hline$\leq 5$ hours & 190 & 10 & 0.002 (Chi square) \\
\hline$\geq 6$ hours & 60 & 10 & \\
\hline \multicolumn{4}{|c|}{ Zone ROP (eyes) } \\
\hline Zone II & 214 & 6 & $<0.000$ I (Chi square) \\
\hline Zone I & 36 & 14 & \\
\hline \multicolumn{4}{|l|}{ PCA (weeks) } \\
\hline Mean \pm SD & $37.5 \pm 2.2$ & $36.2 \pm 1.9$ & 0.03 (t-test) \\
\hline Range & $34-47$ & $32-39$ & \\
\hline \multicolumn{4}{|c|}{ Significant risk factors for unfavorable visual outcome } \\
\hline \multicolumn{4}{|c|}{ Zone ROP (eyes) } \\
\hline Zone II & 68 & 43 & 0.001 (Chi square) \\
\hline Zone I & 11 & 27 & \\
\hline \multicolumn{4}{|c|}{ Significant risk factors for unfavorable refractive outcome } \\
\hline \multicolumn{4}{|c|}{ Zone ROP (eyes) } \\
\hline Zone II & 97 & 9 & $<0.000 \mathrm{I}$ (Chi square) \\
\hline Zone I & 11 & 14 & \\
\hline \multicolumn{4}{|l|}{ PCA (weeks) } \\
\hline Mean \pm SD & $37.6 \pm 1.9$ & $35.9 \pm 1.2$ & $<0.000$ I (t-test) \\
\hline Range & $34-43$ & $34-38$ & \\
\hline
\end{tabular}

Abbreviations: ERP, extraretinal proliferation; ROP, retinopathy of prematurity; PCA, postconceptional age (at treatment); SD, standard deviation.

The average SE for 131 eyes was $-1.26 \mathrm{D} \pm \mathrm{SD} 3.29 \mathrm{D}$ (range +6 to $-9.5 \mathrm{D}$ ). The average $\mathrm{SE}$ in the right and left eyes were $-1.33 \mathrm{D} \pm \mathrm{SD} 3.61 \mathrm{D}$ (range -9.5 to $+6.0 \mathrm{D}$ ) and $-1.20 \mathrm{D} \pm \mathrm{SD} 2.96 \mathrm{D}$ (range -8.5 to $+5.5 \mathrm{D}$ ), respectively. High myopia was found in 23 eyes (17.8\%). Zone I disease was present in $25(19.1 \%)$ eyes, and the mean ERP in the 131 eyes was $4.4 \mathrm{~h} \pm \mathrm{SD} 1.6 \mathrm{~h}$ (range $2-10 \mathrm{~h}$ ).

Zone I disease ( $P=0.001$, Chi square) and lower PCA at treatment $(P<0.0001, t$-test) were significant risk factors for high myopia. Lower BW was found to be a marginally significant $(P=0.06, t$-test) risk factor for high myopia. Sex, single or multiple pregnancies, GA at birth, number of ventilated days, presence of sepsis, IVH, or extent of ERP was not significant for unfavorable refractive outcome.

Table 4 Visual acuity in 149 eyes studied

\begin{tabular}{lllll}
\hline Visual acuity & Right eye & Left eye & Total & $\%$ \\
\hline No LP & 6 & 5 & 11 & 7.4 \\
LP-HM & 5 & 7 & 12 & 8.0 \\
CF-20/400 & 8 & 6 & 14 & 9.4 \\
$20 / 200-20 / 70$ & 9 & 10 & 19 & 12.8 \\
$20 / 60-20 / 50$ & 8 & 6 & 14 & 9.4 \\
20/40-20/20 & 39 & 40 & 79 & 53.0 \\
Total & 75 & 74 & 149 & 100.0 \\
\hline Abbreviations: LP, light perception; HM, hand motion; CF, counting fingers.
\end{tabular}


Table 5 Spherical equivalent in right and left eyes studied $(n=|3|)$

\begin{tabular}{lllll}
\hline $\begin{array}{l}\text { Refractive error } \\
\text { (diopter) }\end{array}$ & Right eye & Left eye & Total & \% of I3 I \\
\hline$>+5.0$ & 3 & 2 & 5 & 3.8 \\
+2.5 to +5 & 2 & 1 & 3 & 2.3 \\
0.25 to +2.25 & 10 & 12 & 22 & 16.8 \\
0 to -2.25 & 33 & 34 & 67 & 51.1 \\
-2.5 to -4.75 & 6 & 5 & 11 & 8.4 \\
-5.0 to -10 & 12 & 11 & 23 & 17.6 \\
$>-10$ & None & None & 0 & 0 \\
Total & 66 & 65 & 13 | & 100 \\
\hline
\end{tabular}

\section{Discussion}

This study of 270 eyes is the first and the largest series reporting the outcomes of infants from the Middle East who had laser-treated ROP before the guidelines of ETROP study ${ }^{18}$ were published. The rate of unfavorable structural outcome in our study was $7.4 \%$ of the treated eyes. The visual acuity of less than $20 / 40$ was seen in $47 \%$ of the 149 eyes for which visual data were available. High myopia was seen in $17.8 \%$ of the 131 eyes studied.

Our rate of unfavorable structural outcome of $7.4 \%$ among the laser-treated eyes is comparable with the studies by Foroozan et $\mathrm{al}^{8}$ and Axer-Siegel et $\mathrm{al},{ }^{11}$ but the mean BW and GA at birth of our series were higher than in these two studies (Table 6). Gilbert et $\mathrm{al}^{21}$ have highlighted the differences in the characteristics of infants with severe ROP in countries with different levels of economic development. Other studies have reported higher rate of unfavorable structural outcome than in our study, ${ }^{9,15,22}$ but the mean BW and GA of the infants in those were lower than in our study population (Table 6). The 6-year follow-up ETROP study (the threshold arm) ${ }^{13}$ reported unfavorable structural outcome in $15.2 \%$ of treated eyes. However, all the treated infants in the ETROP study $^{13}$ had BW $<1251 \mathrm{~g}$, and the mean BW and GA at birth were also lower than in our study. Our rate of unfavorable outcome in the subset of infants with BW $<1251$ g was $9.3 \%$.

Though 148 infants were available for the study of structural outcome, only 81 infants had followed up for 24 months or more. Other authors have also observed high rate of drop out in follow up of laser-treated infants. ${ }^{9,11}$ In our study of 149 eyes of 81 infants, the visual acuity of 20/40 or better was achieved in 79 eyes (53\%), which is comparable with the studies by Gnanaraj et $\mathrm{al}^{4}$ and $\mathrm{Al}$ Ghamdi et al. ${ }^{7}$ Other authors have reported visual acuity of 20/40 or better in $31.5 \%$ to $40 \%$ of the eyes studied. ${ }^{11,13,21}$ McLoone et al, ${ }^{23}$ in a study of 43 eyes, reported visual acuity of 20/40 or better in $73 \%$ of subjects at 11 -year follow up. It is important to note that only $1.5 \%-3 \%$ children aged $6-12$ years have visual acuity of less than $20 / 40$ in the general population. ${ }^{24}$ Even when the structural and functional results are better among the laser-treated infants compared with cryopexy-treated infants, ${ }^{5-7}$ the visual morbidity is still significantly high among ROP infants treated by laser. Hence, infants treated for ROP of the pre-ETROP period need long-term follow up.

It is difficult to compare various studies regarding the visual and refractive outcomes, as the periods of follow up, sample size, and their demographic characteristics, methods of assessment of visual acuity, and criteria of favorable outcomes differ from each other. Table 6 compares various studies regarding the three outcomes studied.

The mean $\mathrm{SE}$ of $-1.26 \mathrm{D}$ in our study is comparable with $-1.5 \mathrm{D}$ and $-1.8 \mathrm{D}$ found by Axer-Siegel et $\mathrm{al}^{11}$ and Al Ghamdi et al, ${ }^{7}$ respectively. Lee et $\mathrm{al}^{9}$ found a lower SE of $-0.4 \mathrm{D}$ in their laser-treated eyes. However, other authors

Table 6 Comparison of studies

\begin{tabular}{|c|c|c|c|c|c|c|c|}
\hline Study & $\begin{array}{l}\text { Number of eyes } \\
\text { (infants ) } \\
\text { studied }\end{array}$ & $\begin{array}{l}\text { Mean } \\
\text { BW* }^{*} \mathrm{~g}\end{array}$ & $\begin{array}{l}\text { Mean GA }{ }^{\dagger} \\
\text { weeks }\end{array}$ & $\begin{array}{l}\text { \% Eyes } \\
\text { unfavorable } \\
\text { structural } \\
\text { outcome }\end{array}$ & $\begin{array}{l}V A \pm \geq 20 / 40 \% \\
\text { (eyes studied) }\end{array}$ & $\begin{array}{l}\text { Myopia of } \geq \mathbf{5} \\
\text { D \% eyes } \\
\text { studied }\end{array}$ & $\begin{array}{l}\text { Follow } \\
\text { up } \\
\text { (months) } \\
\text { Mean }\end{array}$ \\
\hline Axer-Siegel et al" & $194(100)$ & 833.9 & 26 & 7.3 & $38.7(75)$ & $24.6(134)$ & 33.6 \\
\hline Lee et $\mathrm{al}^{9}$ & $76(40)$ & 770 & 25.5 & 14.4 & $\mathrm{NA}^{* *}$ & $10(60)$ & 44 \\
\hline Foroozan et $\mathrm{al}^{8}$ & $120(8 \mid)$ & 770.4 & 25.7 & 9.0 & $\mathrm{NA}^{* *}$ & $\mathrm{NA}^{* *}$ & 44.5 \\
\hline Dejonge et $\mathrm{al}^{3}$ & $61(33)$ & 671 & 24.5 & 5.0 & $\mathrm{NA}^{* *}$ & $N^{* *}$ & 3 \\
\hline Sahni et $\mathrm{al}^{22}$ & $8 I(43)$ & 862 & 26 & 10.7 & $40.07(81)$ & $29.6(81)$ & 36 \\
\hline ETROP study & $303(303)$ & 703 & 25.3 & 15.2 & $31.5(299)$ & $37.6^{14}(197)$ & 72 \\
\hline \multicolumn{8}{|c|}{$(\text { Conventional arm })^{13,14}$} \\
\hline Paysee et $\mathrm{al}^{15}$ & $266(138)$ & 784 & 25.4 & 11.3 & $\mathrm{NA}^{* *}$ & $N^{* * *}$ & 6 \\
\hline Dhawan et al ${ }^{12}$ & 184(93) & 1137 & 29.2 & NA & $\mathrm{NA}^{* *}$ & $31.5(184)$ & 24.2 \\
\hline Present study & $270(\mid 48)$ & 910.8 & 27.4 & 7.4 & $53(149)$ & $17.8(|3|)$ & 35 \\
\hline
\end{tabular}

Notes: "Birth Weight, ${ }^{\dagger}$ Gestational age in weeks, ${ }^{\ddagger}$ visual acuity, ${ }^{* *}$ Not available in the study. Mean follow-up for infants with visual and refractive data. 
have reported higher SE in their studies. ${ }^{12,15,22}$ (Table 6). The prevalence of high myopia among laser-treated ROP eyes has been reported to vary from $6.6 \%$ to $37.6 \%{ }^{4,7,9,11,12,14,22}$ The incidence of high myopia in our study was $17.8 \%$, which is less than in other studies, ${ }^{11,12,22}$ including the conventional arm of the ETROP study. ${ }^{14}$

The degree of myopia has been shown to increase with the severity of ROP. ${ }^{25}$ Our policy of treating ROP earlier, at modified threshold ROP, ${ }^{17}$ may be one of the reasons for the less rate of high myopia in our present study.

However, our rate of high myopia is still higher than the rates observed in studies by Gnanaraj et al, ${ }^{4}$ Lee et al ${ }^{9}$ (Table 6) and $\mathrm{Al} \mathrm{Ghamdi} \mathrm{et} \mathrm{al,}{ }^{7}$ though these studies included the lesser number of eyes.

Hence, even when the diode laser-treated eyes have comparatively less myopia than cryopexy-treated eyes, ${ }^{6,7}$ the occurrence of high myopia is still significantly high in ROP-treated infants and these infants need long-term follow up.

\section{Risk factors}

We studied various risk factors for structural, visual and refractive outcomes and found zone I disease to be the most important risk factor for all the three unfavorable outcomes (Table 3). In our study for structural outcome, zone I disease was present in $50(18.5 \%)$ eyes. Zone I disease may be present in 5\%-29\% of treated ROP eyes. ${ }^{6,8,11,13}$ The adverse effect of ROP in zone I on structural outcome was also observed in the ETROP study, ${ }^{13}$ in both conventionally treated and early-treated prethreshold high-risk eyes. Axer-Siegel et $\mathrm{al}^{11}$ made similar observation regarding structural outcome but did not evaluate the effects statistically. Foroozan et $\mathrm{al}^{8}$ and DeJonge et $\mathrm{al}^{3}$ did not find zone I disease to be a statistically significant risk factor for unfavorable structural outcome.

Disease in zone I was the only risk factor for unfavorable visual outcome (Table 3) in our study. The conventional arm of the ETROP study ${ }^{13}$ also noted poor vision more often in eyes with zone I disease but no statistical significance was mentioned. Other studies ${ }^{4,7,11}$ have also not addressed the importance of zone I disease in visual outcomes.

We found zone I disease to be a strong risk factor $(P<0.0001)$ for high myopia. Davitt et $\mathrm{al}^{14}$ also observed in the ETROP study that in the conventionally treated (threshold ROP) eyes, both myopia and high myopia $\geq 5 \mathrm{D}$ were higher in zone I eyes compared with zone II eyes, though the statistical significance was not mentioned. Other authors who studied the refractive outcomes of laser-treated eyes did not investigate the role of zone 1 disease in the development of high myopia $\geq 5 \mathrm{D}^{11,12,22}$

Eyes with favorable structural outcome (Table 3) were more likely to have been treated at the criteria of ERP $\leq 5 \mathrm{~h}$, as described in the results. This validates the modified guidelines of treatment adapted in our centers. In the 270 eyes of our study, the mean extent of ERP was $4.5 \mathrm{~h}$, which is less than the 6.3-7.8 $\mathrm{h}$ noted in other studies. ${ }^{3,6,8}$ However, the extent of ERP was not found to be significant for unfavorable structural, visual, or refractive outcomes, when analyzed as continuous data by student $t$-test. Dhawan et al ${ }^{12}$ reported a mean ERP of $9.6 \mathrm{~h}$ in their study eyes, and the extent of ERP was a significant risk factor for high myopia.

In our study, the mean PCA at treatment was 37.4 weeks, which is longer than the 36.1 weeks and 35.3 weeks noted in studies by Axer-Siegel et $\mathrm{al}^{11}$ and the ETROP ${ }^{13}$ 6-year follow-up study, respectively. Lower PCA at treatment, in our study, was a significant risk factor for unfavorable structural and refractive outcomes but not for unfavorable visual outcome (Table 3). The lower PCA at treatment may indicate lower GA at birth and hence, a more premature infant, as was observed by Axer-Siegel et al. ${ }^{11}$ However, GA at birth was not found to be a significant risk factor for unfavorable structural outcome in many other studies, including our study, ${ }^{3,5,8,11}$

As observed by other investigators, birth weight was not found to be a significant risk factor for unfavorable structural or visual outcomes in our study. ${ }^{5,8,11}$ However, birth weight was found to be a risk factor with marginal significance for high myopia $(P=0.06)$, in our study. The CRYO-ROP study $^{25}$ also observed the effect of low birth weight on the development of high myopia.

We found that males were more likely to have an unfavorable structural outcome than females $(P=0.054)$. However, Foroozan et $\mathrm{al}^{8}$ did not find gender to be a significant risk factor. We did not find multiple or single birth, number of ventilated days, or presence of IVH to be significant for any of the unfavorable outcomes. Subjects with severe IVH may have poorer vision due to involvement of central visual pathways or optic atrophy. ${ }^{6}$ Axel-Siegel et $\mathrm{al}^{11}$ reported that systemic complications, like sepsis, BPD, $\mathrm{IVH}$, or necrotizing enterocolitis, were not significant for unfavorable structural outcome. However, our study found the presence of sepsis to be a significant risk factor for unfavorable structural outcome (Table 3). Bourla et $\mathrm{al}^{26}$ also found sepsis to be significant for unfavorable structural outcome. In general, sepsis indicates a severely ill infant who needs more oxygen, and this may contribute to severe 
ROP that does not respond to laser treatment. Bourla et $\mathrm{al}^{26}$ found mechanical ventilation to be significant for unfavorable outcome. However, the number of ventilated days was not significant for unfavorable outcomes in our study.

We found strabismus in $21(25.9 \%)$ subjects who had follow up of at least 24 months. Strabismus is common in ROP-treated subjects and may be seen in $16.3 \%-39 \%{ }^{7,11,12,23}$

\section{Conclusion}

Though this study is retrospective and has varying periods of follow up for structural, functional, and refractive outcomes, it has shown some important findings. A significant number of infants treated for severe ROP developed visual and refractive morbidities. Zone I disease was shown to be a highly significant risk factor for unfavorable structural, visual, and refractive outcomes. The follow up of laser-treated infants needs to be improved in our population.

\section{Acknowledgment}

This paper was presented as a free paper at a Euretina meeting held on 4th September 2010 in Paris, France. This meeting was conducted by European Society of Retina Specialists.

\section{Disclosure}

This study did not receive any financial support. None of the authors have any financial interest in the study or in the instruments used in this study.

\section{References}

1. Gilbert C, Rahi J, Eckstein M, Eckstein M, O’Sullivan J, Foster A. Retinopathy of prematurity in middle-income countries. Lancet. 1997;350(9070):12-14.

2. Cryotherapy for Retinopathy of Prematurity Cooperative Group. Multicenter trial for cryotherapy for retinopathy of prematurity: Preliminary results. Arch Ophthalmol. 1988;106(4):471-479.

3. DeJonge MH, Ferrone PJ, Trese MT. Diode laser ablation for threshold retinopathy of prematurity: short-term structural outcome. Arch Ophthalmol. 2000;118(3):365-367.

4. Gnanaraj L, Brennan R, Cottrell DG. Retinopathy of prematurity in practice. II: long-term results following treatment for threshold disease. Eye (Lond). 2003;17(2):189-193.

5. Paysse EA, Lindsey JL, Coats DK, Contant CF Jr, Steinkuller PG. Therapeutic outcomes of cryotherapy versus transpupillary diode laser photocoagulation for threshold retinopathy of prematurity. J AAPOS. 1999;3(4):234-240.

6. Pearce IA, Pennie FC, Gannon LM, Weindling AM, Clark DI. Three year visual outcome for treated stage 3 retinopathy of prematurity: cryotherapy versus laser. Br J Ophthalmol. 1998;82(11):1254-1259.

7. Al Ghamdi A, Albiani DA, Hodge WG, Clarke WN. Myopia and astigmatism in retinopathy of prematurity after treatment with cryotherapy or laser photocoagulation. Can J Ophthalmol. 2004;39(5): $521-525$.
8. Foroozan R, Connolly BP, Tasman WS. Outcomes after laser therapy for threshold retinopathy of prematurity. Ophthalmology. 2001;108(9):1644-1646.

9. Lee GA, Hilford DJ, Gole GA. Diode laser treatment of pre-threshold and threshold retinopathy of prematurity. Clin Experiment Ophthalmol. 2004;32(2):164-169.

10. Essex RW, Carden SM, Elder JE. Two year results of laser treatment for retinopathy of prematurity at a single neonatal intensive care unit. Clin Experiment Ophthalmol. 2005;33(4):390-394.

11. Axer-Siegel R, Maharshak I, Snir M, et al. Diode laser treatment of retinopathy of prematurity: anatomical and refractive outcomes. Retina. 2008;28(6):839-846.

12. Dhawan A, Dogra M, Vinekar A, Gupta A, Dutta S. Structural sequelae and refractive outcome after successful laser treatment for threshold retinopathy of prematurity. J Pediatr Ophthalmol Strabismus. 2008;45(6):356-361.

13. The Early Treatment for Retinopathy of Prematurity Group; Good WV, Hardy RJ, Dobson V, et al. Final visual acuity results in the Early Treatment for Retinopathy of Prematurity Study. Arch Ophthalmol. 2010;128(6):663-671.

14. Davitt BV, Dobson V, Good WV, et al; for the Early Treatment for Retinopathy of Prematurity Cooperative Group. Prevalence of myopia at 9 months in infants with high-risk prethreshold retinopathy of prematurity. Ophthalmology. 2005;112(9):1564-1568.

15. Paysse EA, Hussain MA, Miller AM, Brady McCreery KM, Coats DK. Pulsed mode versus near-continuous mode delivery of diode laser photocoagulation for high-risk retinopathy of prematurity. JAAPOS. 2007;11(4):382-392.

16. Al-Amro SA, Al-Kharfi TM, Thabit AA, Al-Mofada SM. Retinopathy of prematurity at a university hospital in Riyadh, Saudi Arabia. Saudi Med J. 2003;24(7):720-724.

17. Wani VB, Kumar N, Sabti K, et al. Results of screening for retinopathy of prematurity in a large nursery in Kuwait: incidence and risk factors. Indian J Ophthalmol. 2010;58(3):204-208.

18. Early Treatment for Retinopathy of Prematurity Cooperative Group. Revised indications for the treatment of retinopathy of prematurity: results of the Early Treatment for Retinopathy of Prematurity randomized trial. Arch Ophthalmol. 2003;121(12):1684-1694.

19. Fleming TN, Runge PE, Charles ST. Diode laser photocoagulation for prethreshold, posterior retinopathy of prematurity. Am J Ophthalmol. 1992;114(5):589-592.

20. Cryotherapy for Retinopathy of Prematurity Cooperative Group. The natural ocular outcome of premature birth and retinopathy. Status at 1 year. Arch Ophthalmol. 1994;112(7):903-912.

21. Gilbert C, Fielder A, Gordillo L, et al; for the International NO-ROP Group. Characteristics of infants with severe retinopathy of prematurity in countries with low, moderate, and high levels of development: implications for screening programs. Pediatrics. 2005;115(5):e518-e525.

22. Sahni J, Subhedar NV, Clark D. Treated threshold stage 3 versus spontaneously regressed subthreshold stage 3 retinopathy of prematurity: a study of motility, refractive, and anatomical outcomes at 6 months and 36 months. Br J Ophthalmol. 2005;89(2):154-159.

23. McLoone E, O'Keefe M, McLoone S, Lanigan B. Long term functional and structural outcomes of laser therapy for retinopathy of prematurity. Br J Ophthalmol. 2006;90(6):754-759.

24. O'Donoghue L, McClelland JF, Logan NS, Rudnicka AR, Owen CG, Saunders KJ. Refractive error and visual impairment in school children in Northern Ireland. Br J Ophthalmol. 2010;94(9):1155-1159.

25. Quinn GE, Dobson V, Kivlin J, et al. Prevalence of myopia between 3 months and $51 / 2$ years in preterm infants with and without retinopathy of prematurity. Cryotherapy for Retinopathy of Prematurity Cooperative Group. Ophthalmology. 1998;105(7):1292-1300.

26. Bourla DH, Gonzales CR, Valijan S, Yu F, Mango CW, Schwartz SD. Association of systemic risk factors with the progression of laser-treated retinopathy of prematurity to retinal detachment. Retina. 2008;28(Suppl 3):S58-S64. 


\section{Publish your work in this journal}

Clinical Ophthalmology is an international, peer-reviewed journal covering all subspecialties within ophthalmology. Key topics include: Optometry; Visual science; Pharmacology and drug therapy in eye diseases; Basic Sciences; Primary and Secondary eye care; Patient Safety and Quality of Care Improvements. This journal is indexed on
PubMed Central and CAS, and is the official journal of The Society of Clinical Ophthalmology (SCO). The manuscript management system is completely online and includes a very quick and fair peer-review system, which is all easy to use. Visit http://www.dovepress.com/ testimonials.php to read real quotes from published authors. 